\title{
KARAKTERISTIK POTENSI ANGIN SEBAGAI SUMBER ENERGI TERBARUKAN DI INDONESIA DARI DATA SATELIT REMOTE SENSING
}

\author{
I Ketut Swardika ${ }^{1}$, Putri Alit Widyastuti Santiary ${ }^{2}$ \\ 1,2Teknik Elektro, Politeknik Negeri Bali, Bukit Jimbaran, Kuta Selatan, 803642 \\ Email: ${ }^{1}$ swardika@pnb.ac.id
}

\begin{abstract}
Abstrak
Abstrak-- Perubahan iklim dan pemanasan global terkait dengan penelitian solar energi banyak dilakukan, namum potensi energi angin belum secara detail dipetakan di Indonesia. Penelitian ini bertujuan memetakan, karakteristik dan potensi angin sebagai energi terbarukan dari data long-term (1997-2009) satellite remote sensing. Arah (WD) dan kecepatan angin (WS) di Indonesia didapat dari data sensor microwave dan scatterometer pada tahun-tahun operasional satelit sbb: ADEOS(1997), DMSP(1998-1999), AMI(1997-1999), QuikSCAT (1999-2009). Keseluruhan data dipraproses dengan grid $0,25^{\circ}$ dan resolusi temporal bulanan. Karakteristik WD dan WS secara regional, dan zonal-longitudinal diungkap dengan statistik. Estimasi energi listrik didapat dari energi kinetik bilah turbin per-unit waktu. Konversi energi menggunakan kurva-daya dan parameter teknis dari 1,50 dan 3,40 MW (GE 1,5s , 3,4-137 model) turbin angin instalasi onshore dengan $25 \mathrm{~km}^{2}$ per-titik dan $15 \%$ ketersediaan area. Hasil menunjukkan karakteristik umum WS rendah di perairan Indonesia $\left(<3,7 \mathrm{~ms}^{-1}\right)$. WS tinggi diarea utara-selatan Jawa-Sumatra dan diperairan Banda $\left(<6,9 \mathrm{~ms}^{-1}\right)$. Zonal-Seaseonal variabilitas angin didaerah ekuator WD, WS sangat stabil. Peningkatan derajat zonal (5deg $>$ ), kurva angin spesifik mengikuti area belahan bumi utara-selatan menyilang dibulan April, Oktober. Angin muson utara-barat dan selatan-timur jelas terlihat hanya diperairan utara-barat Jawa-Sumatra. WS bekisar $0-25,20 \mathrm{~ms}^{-1}$, rata-rata $6.64 \mathrm{~ms}^{-1}$ dengan Std. 1,64 ms ${ }^{-1}$. Estimasi pembangkitan energi listrik berkisar 104,0 s/d 2230,5 kWh per-titik grid instalasi.
\end{abstract}

Kata Kunci: Karakteristik. Energi, Angin, Satelit, Pembangkitan

\begin{abstract}
Global warming, climate changes mostly associates with solar-renewable energy; however wind-energy potential has no detail reports in Indonesia. This study aims to mapping of characteristics and potential of wind as renewable-energy from long-term (1997-2009) satellite remote-sensing. Wind direction (WD), speed (WS) derives from microwave/ scatterometer sensor on satellite operational years as follows: ADEOS (1997), DMSP (1998-1999), AMI (1997-1999), QuikSCAT (1999- 2009). Data processed into 0.25 grid, monthly temporal resolution. The regional characteristics of WD/WS, seasonal and zonal-longitudinal reveals by statistic. Electrical energy derives from kinetic energy of turbine-blades per-unit time. Energy conversion uses power-curves and technical parameters of 1.50 and 3.40 MW (GE 1.5s, 3.4137 models) onshore installations with $25 \mathrm{~km}^{2}$ per point, $15 \%$ availability area. Result shows WS has low characteristics in Indonesian-waters $\left(<3.7 \mathrm{~ms}^{-1}\right)$. WS has high at north-south JavaSumatra, Banda waters $\left(<6.9 \mathrm{~ms}^{-1}\right)$. The zonal-seasonal wind variability of WD, WS stables at equator. Increases of degree-zonal (>5deg), wind curve follows north-south hemisphere characteristics and crosses in April, October. The north-west, south-east monsoon shows clearly only on north-western of Java-Sumatra waters. WS has range of 0-25,20ms-1 average $6.64 \mathrm{~ms}^{-1}$ with Std. 1,64ms $\mathrm{s}^{-1}$. With these WS, generation of electrical energy has range from 104.0 to $2230.5 \mathrm{kWh}$ per-point installation grid.
\end{abstract}

Keywords: Characteristics. Energy, Wind, Satellite, Generation 


\section{PENDAHULUAN}

Pemanasan global dan perubahan iklim sudah secara nyata akan dihadapi akibat penggunaan berlebih bahan fosil sebagai sumber energi utama dunia (Sacuta, Young dan Worth, 2015). Pembangkitan energi dan tranportasi meningkat sejalan dengan pertumbuhan populasi dunia yang mencapai tujuh milyar lebih. (Coyle dan Simmons, 2014). Dengan pertumbuhan konsumsi listrik dunia sebesar 2,4 persen sampai tahun 2030 (Johnson et al., 2015). Indonesia menggunakan lebih dari 550 juta ton batubara sebagai produksi energi utama

Penelitian dan pengembangan potensi dan implementasi energi baru terbarukan (EBT) mulai bangkit dengan banyaknya masyarakat mengenal dan mengetahui segi ekonomi dari solar PV sebagai sumber energi listrik alternatif (Bazilian et al., 2013). Pemerintah Indonesia sendiri bersemangat meningkatkan EBT untuk mencapai 23 persen dari total bauran energi nasional pada tahun 2025 mendatang (Pusdatin ESDM 2014). Namun, biaya pembangkitan dari solar PV masih tinggi, tidak dapat secara ekonomi bersaing langsung dengan sistem pembangkitan konvensional. Kecuali didaerahdaerah yang jauh dimana ulititas daya tidak tersedia dan biaya transmisi daya menjadi penghambat.

Pada skala biaya energi yang besar, generator turbin angin sekarang mampu bersaing dan menjadi sumber daya listrik dengan teknologi paling kompetitif dibandingkan dengan sistem pembangkitan konvensional. Dengan sumber angin berlimpah dan ramah lingkungan, menjadi hal yang penting dalam perencanaan energi dunia (Jacobson dan Archer, 2012; Patel, 2005).

Potensi EBT dari angin belum banyak diteliti dan dipetakan secara detail di Indonesia. Walaupun Indonesia memiliki garis pantai yang sangat panjang, namum kecepatan angin tergolong rendah (Fikri dan Suryopratomo, 2013). Pengembangan turbin angin banyak dilakukan di eropa menurut letak geografis dan aspek meteorologi lingkungan disana. Setiap turbin angin didesain secara khusus sehingga mampu beroperasi optimal dengan kondisi meteorologi tempat dilakukan instalasi. Penelitian ini bertujuan memetakan, karakteristik dan potensi angin sebagai sumber EBT. Batasan-batasan seperti ketersediaan data meteorologi didekati dengan menggunakan data satelit remote sensing. Potensi estimasi daya pembangkitan secara sederhana didapat dari ketersediaan kurva-daya dari model manufaktur turbin angin.

\section{METODE}

Data angin berupa kecepatan angin (WS $\mathrm{m} \mathrm{s}^{-1}$ ) dan arah angin (WD ${ }^{\circ}$ ) didapat dari arsip data-data yang dipublikasikan lebih dari sepuluh tahun oleh space agency dunia seperti NASA Goddard Space Flight Center (GSFC), NASA Jet Propulsion Laboratory (JPL), Remote Sensing Systems (REMSS), French ERS Processing and Archiving Facility and Research Institute for Exploitation of the Sea (IFREMER/CERSAT) dan JAXA Earth Observation Research Center (EORC). Data berupa global level-3 monthly data. Data-data yang tersedia tidak memiliki format yang sama sehingga dilakukan proses kompilasi ulang menjadi 40 derajat latitude, 100 derajat longitude dengan ukuran grid sebesar 0,25 derajat $\left(1^{\circ}=111 \mathrm{~km}\right)$.

Tabel 1

Data dan spesifikasi teknis satellite remote sensing observasi angin

\begin{tabular}{|c|c|c|c|c|}
\hline Paramete & & WS, U- & WS, WD & \\
\hline Unit & & $\left(\mathrm{m} \mathrm{s}^{-1}\right)$ & $\left(\mathrm{m} \mathrm{s}^{-1}\right),\left(^{\circ}\right)$ & \\
\hline Sensor & NSCAT & SSM/I & AMI & SeaWinds \\
\hline Satelit & ADEOS & DMSP & ERS & $\begin{array}{c}\text { QuickSC } \\
\text { AT }\end{array}$ \\
\hline Tahun & 1997 & $\begin{array}{l}1998- \\
1999\end{array}$ & 1997-1999 & $\begin{array}{c}1999- \\
2009\end{array}$ \\
\hline Spasial & $1^{\circ}$ & $0.25^{\circ}$ & $1^{\circ}$ & $0.25^{\circ}$ \\
\hline resolusi & & & & \\
\hline Swath & $600 \mathrm{~km}$ & $1400 \mathrm{~km}$ & $500 \mathrm{~km}$ & $1800 \mathrm{~km}$ \\
\hline $\begin{array}{l}\text { Orbit } \\
\text { cycle }\end{array}$ & 1 day & 1 day & 1 day & 1 day \\
\hline $\begin{array}{l}\text { Orbit } \\
\text { Time }\end{array}$ & $10: 30$ & $\begin{array}{c}6: 00,18: 0 \\
0\end{array}$ & $10: 00$ & $\begin{array}{c}\text { 6:00,18:0 } \\
0\end{array}$ \\
\hline Kanal & $14 \mathrm{Ghz}$ & $\begin{array}{c}19.35 \mathrm{Ghz} \\
37 \mathrm{Ghz}\end{array}$ & $5.4 \mathrm{Ghz}$ & $13.4 \mathrm{Ghz}$ \\
\hline $\begin{array}{l}\text { Data } \\
\text { center }\end{array}$ & $\begin{array}{l}\text { IFREME } \\
\text { R/ } \\
\text { CERSAT }\end{array}$ & REMSS & $\begin{array}{l}\text { IFREMER/ } \\
\text { CERSAT }\end{array}$ & REMSS \\
\hline $\begin{array}{c}\text { ftp/http } \\
\text { site }\end{array}$ & $\begin{array}{c}\text { ftp. } \\
\text { ifremer.fr }\end{array}$ & $\begin{array}{c}\text { ftp.remss. } \\
\text { com }\end{array}$ & $\begin{array}{c}\text { ftp. } \\
\text { ifremer.fr }\end{array}$ & $\begin{array}{c}\text { ftp.remss. } \\
\text { com }\end{array}$ \\
\hline
\end{tabular}

Satellite remote sensing (RS) membawa sensor radar scatterometer atau sensor passive microwave radiometer. RS mengukur angin secara tidak langsung dari riak gelombang kapiler permukaan air laut. RS tidak dapat mengukur angin di daratan. Riak gelonbang kapiler permukaan air laut mengemisi energi radian yang dapat diobservasi pada spektrum gelombang mikro. Permukaan air laut yang tenang mengemisi energi radian dengan karakteristik sangat terpolarisasi. Saat permukaan air laut beriak emisi energi radian meningkat dan 
kurang terpolarisasi. WS diukur dari perbedaan besar emisi pada dua kanal frekuensi yang berbeda. WS dapat diestimasi dengan derajat akurasi yang timggi oleh karena memiliki relasi yang unik pada radiative transfer equation dengan brightness temperature (Yin et al., 2017). Radar scatterometer mengukur WS dan WD secara tidak langsung dari radar backscatter riak gelonbang permukaan air laut. Vektor angin didapat dengan cara multiple looks pada area observasi yang sama pada sudut azimuth dan polarisasi yang berbeda-beda. Relasi antara besar radar backscatter dengan WS dan WD didapat dari geophysical model function (Ricciardulli dan Wentz, 2015).

Karakteristik dan potensi angin dihitung dan dianalisa dengan statistik. Dari luasan area Indonesia terdapat 160 baris dan 400 kolom grid untuk setiap bulan data. Zonal komponen atau WD arah barat-timur $(U-W S)$ dan Meridonal komponen atau WD arah utara-selatan $(V-W S)$ dihitung dengan persamaan (1).

$\mathrm{U}-\mathrm{WS}=\mathrm{WS} \sin \left(\frac{\pi}{180} \mathrm{WD}\right) \quad \mathrm{V}-\mathrm{WS}=\mathrm{WS} \cos \left(\frac{\pi}{180} \mathrm{WD}\right)$

Zonal klimatologi rata-rata dari WS, WD, U-WS dan V-WS dihitung pada derajat $20^{\circ} \mathrm{S}, 15^{\circ} \mathrm{S}, 10^{\circ} \mathrm{S}$, $5^{\circ} \mathrm{S}, \mathrm{EQ}, 5^{\circ} \mathrm{N}, 10^{\circ} \mathrm{N}, 15^{\circ} \mathrm{N}, 20^{\circ} \mathrm{N}\left(\overline{\text { Zonal }}_{\mathrm{m}, \mathrm{k}}\right)$ menggunakan persamaan (2). Dimana $N$ adalah total grid pada rentang tahun (1997-2009) tanpa grid dengan status no-data.

$\overline{\text { Zonal }}_{\mathrm{m}, \mathrm{k}}=\frac{1}{\mathrm{~N}} \sum_{\mathrm{i}=1}^{\mathrm{N}}$ Zonal $_{\mathrm{m}, \mathrm{k}}$

Pola vektor angin disetiap grid didapat setelah melakukan perhitungan rata-rata klmatologi untuk komponen vektor angin ( $\left.\overline{\mathrm{U}}-\mathrm{WS}_{\text {grid }}\right)$ dan $\left(\overline{\mathrm{V}}-\mathrm{WS}_{\text {grid }}\right.$ ) menggunakan persamaan (3). Dimana $M$ adalah rentang tahun (1997-2009). Selanjutnya pola klimatologi vektor angin diplot dengan Grads tool.

${\overline{\mathrm{U}}-\mathrm{WS}_{\text {grid }}}=\frac{1}{\mathrm{M}} \sum_{\mathrm{i}=1}^{\mathrm{M}} \mathrm{U}-\mathrm{WS}_{\mathrm{i}} \quad \overline{\mathrm{V}}-\mathrm{WS}_{\text {grid }}=\frac{1}{\mathrm{M}} \sum_{\mathrm{i}=1}^{\mathrm{M}} \mathrm{V}-\mathrm{WS}_{\mathrm{i}}$

Standar deviasi setiap WS pada setiap grid ( $\sigma_{\text {grid }}$ ) menggunakan persamaan $(4,5)$.

$\sigma_{\text {grid }}^{2}=\frac{1}{\mathrm{M}-1} \sum_{\mathrm{i}=1}^{\mathrm{M}}\left(\mathrm{WS}_{\mathrm{i}}-\overline{\mathrm{WS}}_{\text {grid }}\right)^{2}$

$\sigma_{\text {grid }}=\sqrt{\sigma_{\text {grid }}^{2}}$
Energi kinetik angin yang memotong bilah turbin per unit time $(\mathrm{P})$ tergantung pada densitas udara $(\rho)$. Area yg tersapu oleh bilah rotor $\left(\pi r^{2}\right)$ dan volume WS $\left(V^{3}\right)$ tereduksi oleh efisiensi energi faktor $\left(f_{p}\right)$ dihitung dengan persamaam (6) (Lu, McElroy dan Kiviluoma, 2009):

$\mathrm{P}=\frac{1}{2} \rho \pi \mathrm{r}^{2} \mathrm{f}_{\mathrm{p}} \mathrm{v}^{3}$

Konversi energi bervariasi tergantung volume WS, dari rendah, moderat dan tinggi dan terdapat mekanisme mencegah kerusakan akibat WS yang berlebih. Efisiensi energi kinetik yang memotong bilah turbin pada WS yang diberikan dikonvesi menjadi listrik tergantung pada detail spesifikasi desain turbin yang mana direpresentasikan kedalam model kurva-daya turbin yang dipilih. Biasanya kurva-daya dihitung dengan asumsi densitas udara sebesar $1.225 \mathrm{~kg} / \mathrm{m}^{3}$, temperatur $15^{\circ} \mathrm{C}$ pada tekanan 1 atmosfir. Koreksi volume WS dapat dilakukan jika terdapat perbedaan kondisi diatas dengan persamaan (7). Dimana P tekanan udara, T temperatur dan $\mathrm{R}$ atmospherik gas konstan (287,05 N.m/(kg.K).

$\mathrm{V}_{\text {koreksi }}=\left(\frac{\mathrm{P} . \mathrm{T}}{1.225 \cdot \mathrm{R}}\right)^{1 / 3} \cdot \mathrm{V}_{\text {original }}$

Pada penelitian ini menggunakan model yang tersedia pada General Electric wind turbine yaitu 1,50 MW dan 3,40 MW (GE 1.5s, 3.4-137 model) turbin angin instalasi onshore. Energi kinetik angin yang didapat dari analisa diatas direlasikan secara sederhana dengan kurva-daya turbin angin berdasarkan model tersebut. Berikut ini kurva-daya GE 1,5s, 3,4-137 model.

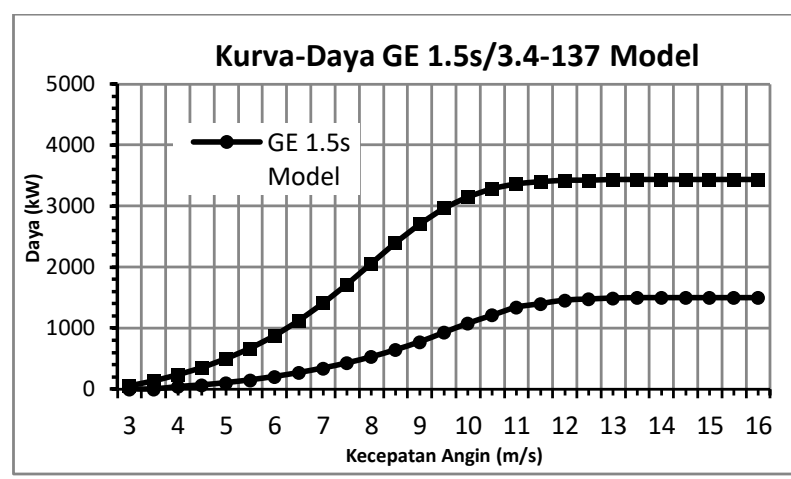

Gambar 1.

Kurva-Daya GE 1,5s MW dan 3,4-137 MW Model

Instalasi turbin angin membutuhkan ruang jarak antar turbin guna meminimalisasi interferensi aliran udara akibat interaksi putaran antar bilah turbin. Dengan luasan grid $0,25^{\circ}$ persegi $\left( \pm 25 \mathrm{Km}^{2}\right)$ cukup 
untuk mengatasi interferensi angin di atas. Pembatas ini membatasi tujuan memaksimalkan pembangkitan daya per turbin dengan jumlah instalasi per grid area (Dhanju, Whitaker dan Kempton, 2008). Mendapatkan jumlah instalasi dan ruang jarak antar turbin yang optimal perlu memperhatikan banyak faktor seperti biaya instalasi perturbin, pembanguan infrastruktur, instalasi transmisi daya dan biaya operasi dan perawatan. Juga diperhitungkan faktor kapasitas akibat dimana kondisi WS sangat rendah sehingga tidak terdapat pembangkitan energi listrik.

\section{HASIL DAN PEMBAHASAN}

Dengan rentang tahun dari tahun 1997 sampai tahun 2009, Hasil perhitungan statistik untuk keseluruhan data ditunjukkan pada Tabel 2 berikut.

Tabel 2.

Statistik WS pada rentang tahun 1997-2009

\begin{tabular}{lc}
\hline Parameter & WS $\left(\mathrm{m} \mathrm{s}^{-1}\right)$ \\
\hline Minimum & 0.00 \\
\hline Maksimum & 26.20 \\
\hline Rata-rata & 6.64 \\
\hline $\begin{array}{l}\text { Standar } \\
\text { deviasi }(\sigma)\end{array}$ & 1.64 \\
\hline
\end{tabular}

WS rata-rata sebesar $6,64 \mathrm{~m} \mathrm{~s}^{-1}$ dengan standar deviasi 1,64 $\mathrm{m} \mathrm{s}^{-1}$, WS berkisar 5,0 sampai dengan $8,28 \mathrm{~m} \mathrm{~s}^{-1}$. Data global menunjukkan, sekitar $13 \%$ stasiun cuaca melaporkan rata-rata tahunan WS lebih dari $6,9 \mathrm{~m} \mathrm{~s}^{-1}$. WS pada ketinggian $10 \mathrm{~m}$ diatas permukaan laut rata-rata global sebesar $6,64 \mathrm{~m} \mathrm{~s}^{-1}$ dan pada daratan sebesar $3,28 \mathrm{~m} \mathrm{~s}^{-1}$. Perubahan ketinggian WS lebih tinggi, pada ketinggian $80 \mathrm{~m}$ WS berkisar $8,60 \mathrm{~m} \mathrm{~s}^{-1}$ dan 4,54 $\mathrm{m} \mathrm{s}^{-1}$ untuk diatas permukaan laut dan daratan (Archer dan Jacobson, 2005). WS relatif rendah dikarenakan posisi geografis Indonesia berada di daerah katulistiwa.

Dari meteorologi, pada daerah subtropik belahan bumi utara dan selatan, angin bertiup tetap sepanjang tahun menuju ke barat disebut angin pasat (tradewinds). Di sekitar katulistiwa, kedua angin pasat bertemu (konvergen) dan disebut intertropical convergens zone (ITCZ) (Nicholson, et al., 2018). Akibat temperatur daerah tropis tinggi, massa udara naik secara vertikal (konveksi). Sehingga daerah ini memiliki karakteristik angin yang tenang (doldrums) (Klocke et al., 2017).

Dilihat dari datasheet GE 1,5 MW kecepatan angin nominal dibutuhkan sebesar 13,0 $\mathrm{m} \mathrm{s}^{-1}$ (rated) dan minimal sebesar $4,0 \mathrm{~m} \mathrm{~s}^{-1}$ (cut-in). Dengan kondisi WS berkisar 5,0-8,28 $\mathrm{m} \mathrm{s}^{-1}$ pembangkitan energi diharapkan dapat terjadi. Pengoperasian turbin pada cut-in WS yang rendah menurunkan perfoman akibat separator laminar dan gelembung separator laminar pada bilah turbin. Ini terjadi karena bilangan Reynolds $(\mathrm{Re})$ rendah akibat WS yang rendah dan kecilnya ukuran rotor. Diperlukan airfoil dengan desain khusus untuk beroperasi pada Re yang rendah sehingga dapat menaikkan startup torsi dan meningkatkan perfoman turbin. Dengan ini turbin dapat dioperasikan pada cut-in WS berkisar 2-3 $\mathrm{m} \mathrm{s}^{-1}$ (Singh dan Ahmed, 2013).

WS mudah dipengaruhi oleh hambatan dan topograpi, bervariasi dengan ketinggian sehingga WS dapat memiliki karakteristik yang random. Akibatnya reabilitas pembangkitan energi listrik sulit dipenuhi dan dibutuhkan sistem pengatur daya cadangan (Lie et al., 2009).

Seasonal variabiliti U-WS ditunjukkan pada gambar $2 a$ dan $b$ di bawah ini. Pada gambar terlihat karakteristik U-WS belahan bumi utara-selatan jelas terlihat. Pola WD memotong pada bulan April dan Oktober. Di ekuator (EQ), tidak terlihat arah WD yang signifikan. Pada gambar $2 a$, peningkatan derajat lintang diatas 20 derajat, U-WS pada bagian utara dan selatan mengarah ke barat dengan kecepatan 4,0 $\mathrm{m} \mathrm{s}^{-1}$ sepanjang tahun. Penomena ini menunjukkan adanya angin pasat dari timur-utara dan timur-selatan. Kondisi permukaan air laut di daerah equator yang selalu hangat membuat tekanan atmosfir menjadi rendah, udara berpindah dari lintang tinggi bertekanan tinggi menuju equator. Bumi berotasi dari barat ke timur, udara berhembus dari timur membangkitkan angin pasat.

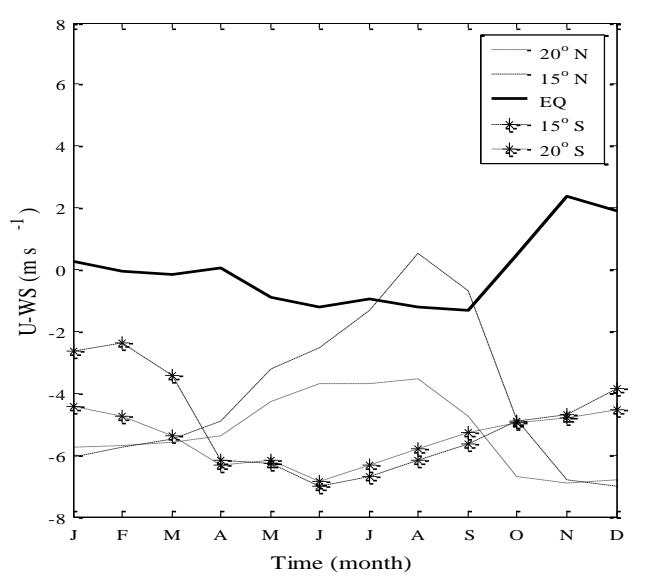

Gambar $2 a$.

Zonal seasonal variabiliti U-WS $\left(\mathrm{m} \mathrm{s}^{-1}\right)$. WD menuju timur (positip) dan menuju barat (negatip). Angin pasat dari timur terlihat pada lintang $15^{\circ}-$ $20^{\circ}$. Didaerah equator WS sangat rendah dan WD stabil

Dilihat dari karakteristik U-WS diatas perencanaan posisi turbin angin di garis katulistiwa tidak tepat. 
Kecepatan U-WS sangat rendah berkisar antara 2,0$3,0 \mathrm{~m} \mathrm{~s}^{-1}$. Cut-in WS minimal sulit didapatkan, walaupun mungkin terjadi anomali WS yang tinggi dan tidak terjadi perubahan WD yang siginifikan. Pada lintang tinggi berkisar $15^{\circ}-20^{\circ}$, WD didominasi oleh arah angin pasat atau angin menuju ke barat atau westerlies winds (Hansen et al., 2012). Grid instalasi turbin angin dapat diposisikan secara general bilah turbin mengarah ke timur. Pada turbin angin terdapat yawing mekanisme yang memutar turbin sehingga bilah dapat mengikuti arah angin dan tilting mekanisme yang memutar sudut bilah sehingga tetap optimal pada kecepatan angin relatip (Doolan, Moreau dan Brooks, 2012; Schubel dan Crossley, 2012)

Sedangkan gambar $2 b$ menunjukkan karakteristik U-WS untuk posisi lintang kurang dari 10 derajat. Terlihat U-WS lebih jelas memperlihatkan seasonal variabiliti mengikuti karakteristik belahan bumi utara-selatan. Intensitas dan arah timur-barat angin berubah menurut musim. Namun, WD rata-rata tetap mengikuti pola angin pasat yaitu menuju barat. Pola perubahan arah timur-barat musiman ini menunjukkan sistem angin muson di Indonesia.

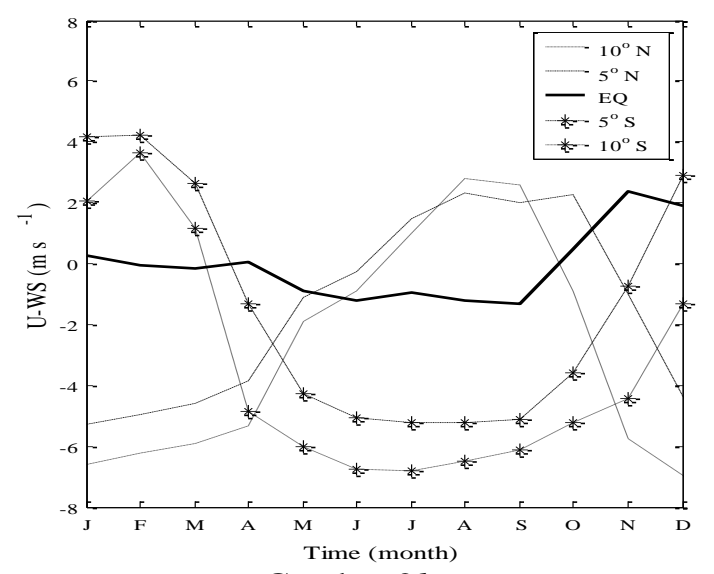

Gambar $2 b$.

Zonal seasonal variabiliti U-WS $\left(\mathrm{m} \mathrm{s}^{-1}\right)$. WD menuju timur (positip) dan menuju barat (negatip). Perubahan arah angin musiman atau angin muson Indonesia pada derajat lintang $5^{\circ}-10^{\circ}$.

Dengan karakteristik angin yang berubahubah mengikuti musim, stabilitas pembangkitan menjadi sangat tergantung musim. Bulan-bulan transisi angin muson Maret-Mei dan SeptemberNovember dimana pada WS paling rendah dibutuhkan sistem cadangan daya dari sistem pembangkitan yang lain atau hybrid. Perubahan WD yang signifikan akibat angin muson timur/barat berimplikasi terhadap perawatan mekanik yang bergerak seperti mekanis gearbox, tilting dan yawing. Beberapa laporan akibat permasalahan pada bilah dan gearbox penyebab utama sistem downtime. Turbin yang baru dan besar malah cenderung lebih sering downtime, untuk menjaga reabilitas pembangkitan kebutuhan akan monitor dan perawatan menjadi tinggi (Pérez et al., 2013).

Besarnya konversi energi kinetik bilah turbin dibatasi adanya daya mekanis downstream atau aliran angin setelah melewati bilah. Daya ini mengurangi konversi koefisien daya $\left(\mathrm{C}_{\mathrm{p}}\right)$ turbin hanya menjadi sebesar 59,3\% atau disebut Betz's limit (Betz, 2013; Şen, 2013). Luaran daya turbin angin secara signifikan bervariasi dengan WS tidak menyebabkan setiap turbin angin memiliki kurvadaya yang unik. Kurva-daya membantu memprediksi tanpa perlu mengetahaui detail teknis dari setiap komponen sistem pembangkitan. (Manwell, McGowan dan Rogers, 2010). Kurvadaya memberikan besaran daya listrik luaran sebagai fungsi dari WS pada posisi ketinggian dari hub. Kurva-daya terdiri dari cut-in, rated dan cut-out WS. Kurva-daya untuk setiap turbin didapat dari test lapangan dan diberikan oleh pabrik pembuatnya (Lydia et al., 2014). Dengan menggunakan model turbin angin dari General Electric dan kondisi angin seperti Tabel 2, didapat estimasi pembangkitan daya listrik seperti pada Tabel 3 berikut ini.

Tabel 3 .

Estimasi daya pembangkitan $(\mathrm{kW})$ dari kurva-daya untuk GE model

\begin{tabular}{ccc}
\hline $\begin{array}{c}\text { avgWS } \div \text { STD } \\
\left(\mathrm{m} \mathrm{s}^{-1}\right)\end{array}$ & $\begin{array}{c}\text { GE 1.5s } \\
(\mathrm{kW})\end{array}$ & $\begin{array}{c}\text { GE 3.4-137 } \\
(\mathrm{kW})\end{array}$ \\
\hline 5.00 & 104.00 & 497.00 \\
\hline 6.64 & 306.50 & 1265.50 \\
\hline 8.28 & 586.00 & 2230.50 \\
\hline $\begin{array}{c}\text { rated } \mathrm{WS} \\
13.00\end{array}$ & 1494.00 & 3430.00 \\
\hline
\end{tabular}

Dari tabel 3 menunjukkan daya pembangkitan untuk model turbin angin GE daya rendah dan tinggi untuk kondisi di Indonesia berkisar antara 104.00 $2230.50 \mathrm{~kW}$ pertitik instalasi.

Jika dibandingkan dengan sistem dari PLTB SIDRAP ladang energi angin pertama di Indonesia, telah terinstalasi 30 titik generator turbin angin dengan menggunakan Gamesa G114-2.5MW model. Dengan target pembangkitan energi listrik sebesar 75 MW, sehingga optimal daya pertitik turbin sebesar 2,5 MW. Perbandingan dapat dilakukan dengan melihat kurva-daya antara model GE 3,4-137 MW dengan Gamesa G114-2,5MW seperti Tabel 4 dibawah ini. 
Tabel 4.

Perbandingan daya pembangkitan $(\mathrm{kW})$ dari kurvadaya untuk GE dengan GAMESA model

\begin{tabular}{ccc}
\hline $\begin{array}{c}\text { avgWS } \div \text { STD } \\
\left(\mathrm{m} \mathrm{s}^{-1}\right)\end{array}$ & $\begin{array}{c}\text { GE 3.4-137 } \\
(\mathrm{kW})\end{array}$ & $\begin{array}{c}\text { Gamesa G114- } \\
2.5 \\
(\mathrm{~kW})\end{array}$ \\
\hline 5.00 & 497.00 & 321.00 \\
\hline 6.64 & 1265.50 & 892.75 \\
\hline 8.28 & 2230.50 & 1617.00 \\
\hline rated $\mathrm{WS}$ & & 2332.00 \\
10.00 & 3430.00 & \\
13.00 & & \\
\hline
\end{tabular}

Kelebihan dari model Gamesa G114-2.5MW adalah memiliki cut-in dan rated WS yang lebih kecil sebesar $2.0 \mathrm{~m} \mathrm{~s}^{-1}$ dan $10,0 \mathrm{~m} \mathrm{~s}^{-1}$. Dengan asumsi kondisi angin rata-rata setiap tahun sebesar $8.28 \mathrm{~m} \mathrm{~s}^{-1}$, model ini hanya membangkitkan energi listrik sebesar $1617.00 \mathrm{~kW}$ atau $1.6 \mathrm{MW}$.

\section{KESIMPULAN}

Kondisi meteorologi angin dengan rentang waktu yang cukup dibutuhkan dalam perencanaan instalasi turbin angin. Secara general keterbatasan data meteorologi dapat dipenuhi dari data satelit remote sensing. Karakteristik angin di wilayah Indonesia berhubungan dengan posisi geografis Indonesia. Potensi angin pada skala rendah untuk pembangkitan energi listrik. Diperlukan desain generator turbin angin dengan mekanis yang spesifik untuk wilayah Indonesia. Pola angin yang berubah arah dan kecepatan menurut musim membuat operasional dan perawatan turbin tinggi. Untuk mendapatkan reabilitas operasional yang optimal sistem grid daya cadangan mungkin perlu diperhitungkan.

\section{DAFTAR PUSTAKA}

Archer, C. L., \& Jacobson, M. Z. (2005). Evaluation of global wind power. Journal of Geophysical Research: Atmospheres, 110(D12).

Bazilian, M., Onyeji, I., Liebreich, M., MacGill, I., Chase, J., Shah, J., \& Zhengrong, S. (2013). Re-considering the economics of photovoltaic power. Renewable Energy, 53, 329-338.

Betz, A. (2013). The maximum of the theoretically possible exploitation of wind by means of a wind motor. Wind Engineering, 37(4), 441446.

Coyle, E. D., \& Simmons, R. A. (2014). Understanding the global energy crisis ( $\mathrm{p}$. 318). Purdue University Press.

Dhanju, A., Whitaker, P., \& Kempton, W. (2008). Assessing offshore wind resources: An accessible methodology. Renewable Energy, 33(1), 55-64.

Doolan, C. J., Moreau, D. J., \& Brooks, L. A. (2012). Wind turbine noise mechanisms and some concepts for its control. Acoustics Australia, 40(1).

Fikri, M. B., \& Suryopratomo, I. K. (2013). Perancangan sudu turbin angin berkecepatan rendah dengan variasi tip speed ratio menggunakan metode momentum elemen sudu (Doctoral dissertation, Universitas Gadjah Mada).

Hansen, K. S., Barthelmie, R. J., Jensen, L. E., \& Sommer, A. (2012). The impact of turbulence intensity and atmospheric stability on power deficits due to wind turbine wakes at Horns Rev wind farm. Wind Energy, 15(1), 183-196.

Jacobson, M. Z., \& Archer, C. L. (2012). Saturation wind power potential and its implications for wind energy. Proceedings of the National Academy of Sciences.

Johnson, N., Krey, V., McCollum, D. L., Rao, S., Riahi, K., \& Rogelj, J. (2015). Stranded on a low-carbon planet: Implications of climate policy for the phase-out of coal-based power plants. Technological Forecasting and Social Change, 90, 89-102.

Klocke, D., Brueck, M., Hohenegger, C., \& Stevens, B. (2017). Rediscovery of the doldrums in storm-resolving simulations over the tropical Atlantic. Nature Geoscience, 10(12), 891.

Lei, M., Shiyan, L., Chuanwen, J., Hongling, L., \& Yan, Z. (2009). A review on the forecasting of wind speed and generated power. Renewable and Sustainable Energy Reviews, 13(4), 915920.

Lu, X., McElroy, M. B., \& Kiviluoma, J. (2009). Global potential for wind-generated electricity. Proceedings of the National Academy of Sciences, 106(27), 10933-10938.

Lydia, M., Kumar, S. S., Selvakumar, A. I., \& Kumar, G. E. P. (2014). A comprehensive review on wind turbine power curve modeling techniques. Renewable and Sustainable Energy Reviews, 30, 452-460.

Manwell, J. F., McGowan, J. G., \& Rogers, A. L. (2010). Wind energy explained: theory, design and application. John Wiley \& Sons.

Nicholson, S. E. (2018). The ITCZ and the seasonal cycle over equatorial Africa. Bulletin of the American Meteorological Society, 99(2), 337348.

Patel, M. R. (2005). Wind and solar power systems: design, analysis, and operation. CRC press. 
Pusdatin ESDM, (2014), Pusat Data dan Teknologi Informasi (Pusdatin) Kementerian Energi dan Sumber Daya Mineral (ESDM).

Pérez, J. M. P., Márquez, F. P. G., Tobias, A., \& Papaelias, M. (2013). Wind turbine reliability analysis. Renewable and Sustainable Energy Reviews, 23, 463-472.

Ricciardulli, L., \& Wentz, F. J. (2015). A scatterometer geophysical model function for climate-quality winds: QuikSCAT Ku-2011. Journal of Atmospheric and Oceanic Technology, 32(10), 1829-1846.

Sacuta, N., Young, A., \& Worth, K. (2015). International Energy Agency (IEA) Greenhouse Gas (GHG) Weyburn-Midale $\mathrm{CO}_{2}$ Monitoring and Storage Project. Petroleum Technology Research Centre Incorporated, Saskatchewan (Canada).

Schubel, P. J., \& Crossley, R. J. (2012). Wind turbine blade design. Energies, 5(9), 34253449.

Singh, R. K., \& Ahmed, M. R. (2013). Blade design and performance testing of a small wind turbine rotor for low wind speed applications. Renewable Energy, 50, 812-819.

Şen, Z. (2013). Modified wind power formulation and its comparison with Betz limits. International Journal of Energy Research, 37(8), 959-963.

Yin, X., Wang, Z., Song, Q., Huang, Y., \& Zhang, R. (2017). Estimate of Ocean Wind Vectors Inside Tropical Cyclones From Polarimetric Radiometer. IEEE Journal of Selected Topics in Applied Earth Observations and Remote Sensing, 10(5), 1701-1714. 